\title{
EL LEXICO COMO FACTOR CONFORMANTE DEL DISCURSO NARRATIVO: EL CASO DE "MESA, SOBREMESA", DE A. ZAMORA VICENTE
}

\author{
Manuel Casado Velarde
}

La atención por la lengua como factor conformante no sólo de la expresión sino también, en algún modo, del contenido, es característica de la ya nutrida producción cuentística de Alonso Zamora Vicente. El fenómeno, como no podía por menos, no ha escapado a los críticos. Refiriéndose al relato Uno es generoso (1972), ha podido afirmar E. Lorenzo que en él Zamora "consigue, como pocos narradores españoles, una secuencia casi magnetofónica, de lo que entendemos por habla coloquial, con sus muletillas, sus frases de relleno, sus incoherencias. sus repeticiones inútiles ${ }^{\$ 1}$.

Es tal la importancia que Zamora Vicente concede a las manifestaciones lingüísticas en sus narraciones, que $E$. de Zuleta ha llegado a sentenciar que la génesis misma de sus relatos "es fundamentalmente lingüística, puesto que desde el habla y por el habla se encarnan y se definen personajes y acontecimientos"2. Ese protagonismo de la lengua se manifiesta en el perspectivismo lingüístico que surge de la alternancia, cuidadosamente lograda, de diferentes niveles y registros de lengua: "A cada personaje, un lenguaje diferenciado según la edad, el sexo, la clase social, la educación; para cada época evocada, su contexto lingüístico propio"3.

1. E. Lorenzo, "Alonso Zamora Vicente, Uno es generoso", en El comentario de textos, 2, Madrid 1974, 247-282, pp. 253-254.

2. E. de Zuleta, "La narrativa de Alonso Zamora Vicente", en Papeles de Son Armadans, LXX (1973), 181-217, pp. 214-215.

3. E. de Zuleta, "La narrativa...", cit., p. 211. No hay que olvidar, en concreto, el interés de Zamora Vicente por el habla de Madrid, materializado en "Una mirada al hablar madrileño", en Lengua, literatura, intimidad, Madrid 1966, 63-73. Cfr. también A. R. Fernández y González, "De las siete salidas de Zamora Vicente a la Plazuela del Conde Lucanor", en Papeles de Son Armadans, LXX (1973), 265-273, p. 272. 
No en vano se ha dicho que los personajes de Zamora Vicente son más locutores que actores. "Estos exhuberantes habladores [...] de Alonso Zamora se desnudan hablando; el creador se venga de ellos y dibuja su retrato, sencillamente con dejar que se expresen a sus anchas" 4 . Por eso sus relatos constituyen "un prodigioso repertorio de habla viviente, en un corte fundamentalmente sincró. nico"s.

Mesa, sobremesa ${ }^{6}$, el último libro de Zamora Vicente, se sitúa claramente dentro de las coordenadas que someramente acabo de apuntar. Desde el punto de vista temático, pertenece decididamente a la dirección neorrealista que engloba toda la producción de Zamora a partir de 1960. Son narraciones de mínima acción, con las solas variantes de los ambientes y de los tipos humanos que se nos presentan. En este caso, los personajes convocados por Zamora Vicente pertenecen a un ámbito social y geográfico homogéneo: la mesocracia madrileña, retratada a través de su cháchara $a$ traque barraque en el trascurso de un banquete de homenaje a un jefecillo ambicioso e hipócrita ${ }^{7}$.

La novela está escrita en una lengua coloquial, en la que al léxico estándar se suman términos procedentes de diversos ámbitos marginales. Una lengua en la que conviven el término culto, de sabor intelectual, y el popular o rural; la vieja voz familiar y el neologismo estudiantil cheli; el vocablo hondamente arraigado en el solar del idioma y el extranjerismo importado ayer; la palabra malsonante y el eufemismo.

Precisamente a la función del léxico como configurador del discurso narrativo dedico el presente estudio. A la vez, pretendo dar una instantánea representativa de las tendencias del vocabulario español actual. Me dedico a este aspecto porque, aun señalándolo, no lo tratan específicamente con enfoque lingüístico otros críticos ${ }^{8}$.

Uno de los rasgos que primero salta a la vista es la adaptación gráfica, a favor de la pronunciación actual, de que son objeto los extranjerismos. Así ocurre con metre (22), ofis (37), chovinistas (48), jipi (50), casetes (56), espich (103), butis (116), lomplei (159), jol (159), sinca-mil (60). Esta adaptación resulta, en ocasiones, distinta de la realizada oficialmente por la Real Academia Española en su última edición $\left(19^{\mathrm{a}}, 1970\right)$ del Diccionario (en adelante, DRAE),

4. D. Alonso, "Notas volanderas sobre el arte de Alonso Zamora Vicente", en Papeles de Son Armadans, LXX (1973), 127-135, p. 135.

5. E. de Zuleta, "La narrativa...", cit., p. 211.

6. Col. Novelas y cuentos, Madrid 1980, 219 pp., Premio Nacional de Literatura.

7. D. Villanueva sitúa esta novela entre las que "intentan ofrecer una visión crítica de nuestra sociedad preferentemente por medio de la captación lingüística". "La novela", en El año literario español 1980, Madrid 1981, p. 24.

8. Cfr. reseñas de J. L. Martín Nogales, Mesa, sobremesa, en Diario de Navarra, 27.XI.80; E. Popeanga, "Una novela de Alonso Zamora Vicente: Mesa, sobremesa", Insula, núm. 411 , feb. 1981, p. 4. 


\section{EL LEXICO COMO FACTOR CONFORMANTE DEL DISCURSO NARRATIVO}

como puede apreciarse en restoranes (98, DRAE: restaurante), clus (97, DRAE: $c l u b)$, pero pubs (116) quizá frenado por pus 'pus'. Vacila en la acentuación de coctel (DRAE): cóctel (89), cocteles (95). Otras formas alienígenas coinciden con las del diccionario oficial: chaqué (54), consomé (37), como era de esperar. Los galicismos caché (116) y crochet $(157)^{9}$, aún no recogidos por el DRAE, presentan su forma originaria.

Otro aspecto gráfico, relativo al léxico, digno de notarse lo constituye la presentación de marcas comerciales sin las habituales iniciales mayúsculas: yankos (141), lotusses (152), chinchón (181), magno (181), tres torres (181), volvo (215), duralex (110), seat (136), el ya citado sinca-mil (60). Aunque estos términos no han sido afectados por el proceso de generalización que ha convertido a otros en apelativos -túrmix, claxon o michelines (140), este último para designar los 'pliegues de grasa en el cuerpo', transparentan de esta manera el grado de familiaridad con que suelen ser empleados en la conversación. (Como es sabido, el término Michelín es denominación comercial de una marca de neumáticos, que se anuncia con una figura humana formada por neumáticos, de modo que su cuerpo es una continuación de protuberancias ${ }^{10}$.)

No podían faltar, en una obra que trata de reflejar la lengua coloquial de hoy, los casos, más o menos arraigados, de acortamientos léxicos: progre (33), porno (40), profe (41), propi (60), poli (66), cole (108), tele (110), mili (117), anti ( $\leftarrow$ antibiótico, 120), presi (158).

Los escasos testimonios de lexicalización de siglas o de combinaciones alfanuméricas $^{11}$ : dekauves (26), sinca-mil (60), seat (136) resultan coherentes con las irónicas alusiones de que son objeto en la novela: me ofrecian un buen enchufe en la JPZ si abandonaba la ZPJ (26); con ese galimatias del COU o del BUP (33); nos debieron poner algo, un narcótico, una droga, esas cosas, ya sabe, SLP, o LSP, o un SOS, o un UCD, o demonios (172).

Aparecen con cierta frecuencia combinaciones léxicas formadas por sustantivo más sustantivo en aposición, del tipo de mesa camilla (27), cena concurso literario (40), ciudadano-empresario-investigador (57), biblioteca monstruo (75), magnetófono casete (122), entrevista-test (129), escapada-charter (211), sofá-cama (110), canciones protesta (205). Algunas se encuentran arraigadas desde mucho tiempo atrás; otras son recientes o invención del autor.

La derivación sufijal refleja parcialmente algunas de las tendencias actuales de la lengua familiar y juvenil: jovenzanos (30), muslamen (23), dentamen (86),

9. Galicismo por ganchillo 'labor de gancho', cfr. M. Seco, Diccionario breve de dudas de la lengua española, Madrid 1979, s.v.

10. Cfr. M. Casado Velarde, Lengua e ideologia. Estudio de "Diario libre", Pamplona 1978, p. 157.

11. Cfr. F. Marcos Marín, Reforma y modernización del español, Madrid 1979, p. 117; M. Casado Velarde, "Creación léxica mediante siglas", Revista Española de Lingüistica, 9 (1979), 67-88. 


\section{MANUEL CASADO VELARDE}

altota (137), grandota (105), ordinariota (105), niñato (72, con significado distinto al registrado por el DRAE). No es de extrañar, para el que conozca el castellano actual, la frecuencia del sufijo -oso, - $a^{12}$ : izquierdoso (99), gafosa (137), zurdoso (199), soberbiosa (212). Otras sufijaciones: progresia (153), marmoteria (106), camareril (45), grasucia (201).

E1 lenguaje de amplios sectores juveniles urbanos que se ha dado en denominar cheli, aflora frecuentemente en boca de personajes que sobrepasan, cabe suponer, ampliamente, la edad referida ${ }^{13}$. Surgen así términos como gachis (23), demasié (31), currante (125), parida (82), chollo (125), pavos 'duros' (125), gandumbas (139), gazucilla (143), carcamal (144), tiberio (151), gilipuertas (157), travolta (214), cubata (216) ${ }^{14}$, naturaca (201), talmente (152), largar 'hablar' (107), diñarla (116), chorras (126), pringarla (125), quinqué (125), palmarla (139), pasota (156); o expresiones como a mi no me enrolla todo ese lio (27), nos fundió la escapada (116), el tipo me marcaba muy bien (126), atacando el consomé (33), son unos piernas (157), etc. Muchos de estos vocablos o expresiones eran ya bien conocidos en tiempos atrás en otros ámbitos, pero han vuelto a ponerse en circulación por quienes no los conocieron.

No faltan, como ya anticipé, los eufemismos, de uso más o menos frecuente en la lengua coloquial, como leñe (120), jobar (172), repistonudos (105), o la serie de expresiones sinónimas integradas por mal café (15), mala uva (13), mala milk (13) y mala levadura (152), por 'mala intención'.

Otro recurso muy frecuentado en la lengua coloquial, y que está presente en las páginas de esta novela, lo constituyen las frases rimadas, en ocasiones con elementos apofónicos, meramente lúdicos, de eficaz efecto humorístico: a otra cosa, mariposa (26), no te enrolles, Charles Boyer (125), de chipendi lerendi (130), demasiado visto ya ese truco, partuco (155), chúpate ésa, marquesa $(156)^{15}$.

Finalmente señalaré algunas de las abundantes creaciones léxicas, de carácter más o menos insólito, que aparecen en Mesa, sobremesa: vascotarra (33), progretarravascoide (33), comidancia ${ }^{16}$ (159), (a la, en la) putaestrasse $(54,155)$,

12. Ya detectada por E. Náñez, La lengua que hablamos. Creación y sistema, Santander 1973, p. 87 , y que atribuye a influjo hispanoamericano: novedoso, exitoso. No lo cita A. Gooch, Diminutive, Augmentative and pejorative suffixes in modern Spanish, Oxford $1970^{2}$.

13. Como he demostrado en Lengua e ideologia..., cit., pp. 183-187, el cheli resulta escasamente innovador de elementos léxicos; más bien se nutre de voces pertenecientes a modalidades lingüísticas marginales (caló, germanía, lenguaje familiar, vulgar, etc.)

14. Cfr. M. Casado Velarde, "Un sufijo de la lengua juvenil: -ata", en Thesaurus. Boletín del Instituto Caro y Cuervo, 36 (1981).

15. Cfr. J. Morawski, "Les formules rimées de la langue espagnole", Revista de Filología Española, 14 (1927), 113-133.

16. Cfr. E. Náñez, La lengua..., cit., pp. 57 ss. 


\section{EL LEXICO COMO FACTOR CONFORMANTE DEL DISCURSO NARRATIVO}

bebestible (64), chupóptero (79), pintologia (93), cagalancia (117), fuerzavivante (213), ennietecer (109), franquiada (114), camelancia (159), apisonadura (213: esos largos años de la dictadura o de la apisonadura).

Obsérvense, en el parlamento que copio a continuación, algunas de las notas apuntadas:

Pues ahí tienes, el viejo [se refiere a su suegro] empezó a morirse en navidades, que nos fundió a base de bien la escapada que nos gusta hacer a la Costa del Sol, a ver, una semanita en Benalmádena, con sus burritos y su cine, chica, una cosa muy bien, con aquel caché que tiene todo, que te respetan y conocen en los bares y en las piscinas, $y$ en los pubs, $y$ en el ayuntamiento, y hasta te hacen un descuentito en las butís... Pues nos fastidió, porque le dio la tarantela, hija, que si se muere, que si no se muere, que médicos para allá y practicantes para acá y venga y dale, con lo caro que se ha puesto ese material, que no das abasto, les pagas a peso de oro y siempre se quedan esperando propinas... Pero lo peor fue la enfermedad en sí, hija, qué enfermedad, algo tan oprobioso... (pp. 116-117).

Independientemente del interés que puedan suponer para el lingüista - como creo haber mostrado - estos testimonios, desde el punto de vista literario es su acumulación, o incluso su sucesión ininterrumpida, lo que los convierte en recurso estitístico. 
